\title{
Thermodynamic Simulation of Organic Rankine Cycle (ORC) for Electricity Generation from Low-grade Waste Heat
}

\author{
Pornrawee Sophonphichet and Surachai Sanitjai
}

\begin{abstract}
This paper proposes the simulation model of Organic Rankine Cycle (ORC) system based on an actual data. The ORC system was installed to recovery waste heat from exhaust gas and jacket water of natural gas engine. The working fluid of ORC is R245fa. Thermodynamic analyses are conducted with variation of evaporating pressure in ORC loop to observe efficiencies and expansion powers of ORC system. The simulation results indicate that about $20 \%$ and $80 \%$ of the total heat absorption are from jacket water and exhaust gas, respectively. The system gives the maximum expansion power of $326 \mathrm{~kW}$ and the maximum exergy efficiency is $21.45 \%$ at 26 bar of evaporating pressure. The maximum recovery efficiency is $8.74 \%$ in which it occurs at 27 bar of evaporating pressure due to the dramatic drop of $\mathbf{R 2 4 5 f a}$ flow rate. From the simulation model, the ORC system should be operated at 26 bar of evaporating pressure to gain the highest benefit with constant waste heat loss.
\end{abstract}

Keywords- Organic Rankine Cycle (ORC), Waste Heat Recovery, Thermodynamic Analysis.

\section{INTRODUCTION}

Internal combustion engines have been used as a primary power source for automobile, long-haul truck, small-scale distribution generation system and etc. However it has low thermal efficiency and around 60-70\% of feeding fuel energy lost as exhaust gas and jacket water [1]. The exhaust gas and jacket water can be recovered and utilized to improve efficiency by many existed waste heat recovery technologies (WHR). Among all technologies Organic Rankine Cycle (ORC) is getting attention for its reliability, compatibility, and efficiency [2]. The ORC is generally similar to conventional Rankine cycle or Steam Rankine Cycle (SRC), but the ORC uses organic refrigerant as working fluid instead of water [3]. One study found that the presence of water, ammonia, and ethanol molecules in Organic working fluid is not appropriate for ORC systems and its thermal efficiency is a function of critical temperature of working fluid [4]. The appropriate organic working fluid for any ORC systems depends on thermo-physical properties, safety, cost, environmental impacts and etc [5]. Most of researches studied waste heat recovery system of diesel engine with simple thermodynamic models and gave a little attention on physical parameters [6]-[9]. The ORC system proposed in this paper can reflect more realistic behavior of the

Pornrawee Sophonchichet is with Department of Mechanical Engineering, King Mongkut's University of Technology Thonburi, Bangkok 10140, Thailand.

Surachai Sanitjai is with Department of Mechanical Engineering, King Mongkut's University of Technology Thonburi, Bangkok 10140, Thailand.
ORC system by considering both of physical parameters of each component and thermodynamic analysis.

\section{DESCRIPTION OF SYSTEM}

The Organic Rankine Cycle model was deployed on account of reducing the waste heat in exhaust gas and jacket water of the power plant which has 6 of V16 gas engines to generate electricity of 7.2 MW. Its speed is constant at 1500 RPM. Natural gas was suitably fed for those engines while the operating engine conditions were given in Table I. The combustion of natural gas engine was assumed to be perfect combustion and the composition of exhaust gas on molar basis was comprised of: $\mathrm{CO}_{2}=4.97 \%, \mathrm{~N}_{2}=74.28 \%, \mathrm{O}_{2}=9.73 \%$ and $\mathrm{H}_{2} \mathrm{O}=11.02 \%$ [10]. The schematic diagram and T-s diagram of the ORC system can be illustrated as in Fig.1 and Fig.2, respectively. The T-s diagram can describe all of the process of system concisely. The red line, blue line and purple line are represented exhaust gas, jacket water and R245fa, respectively.

\begin{tabular}{ccc} 
TABLE I: THE OPERATING ENGINE CONDITION & \\
\hline \hline Parameters & Unit \\
\hline Exhaust temperature & 408 & ${ }^{\circ} \mathrm{c}$ \\
Exhaust backpressure & 10.3 & $\mathrm{mbar}$ \\
Exhaust flow rate & 6,000 & $\mathrm{~kg} / \mathrm{hr}$. \\
Temperature of jacket water & 86 & ${ }^{\circ} \mathrm{C}$ \\
Circulate jacket water pressure & 3.3 & $\mathrm{bar}$ \\
Jacket water flow rate & 50 & $\mathrm{cum} / \mathrm{hr}$. \\
\hline \hline
\end{tabular}

The operation of the system can be described as follow: water at state (R1) in recuperation loop is pumped via pump (P1) to higher pressure at state (R2) to absorb heat from jacket water at state (JW-IN) via the preheat plate heat exchanger (PHX) then water in recuperation loop leaves the heat exchanger at state (R3) and jacket water flows back to engine at state (JW-OUT). In the ORC loop considering R245fa at state (1) is pumped via pump ORC pump and leaves the pump at state (2) before entering shell and tube heat exchanger HE3 to absorb heat from water at state (R3) then water and R245fa leave the heat exchanger at state (R1) and (3), respectively. R245fa at state (3) flows further to enter shell and tube heat exchanger HE2 to absorb heat from water at state (E4) in evaporation loop then water and R245fa leave the heat exchanger at state (E1) and (4), respectively. After that water at state (E1) is pumped by pump P2 to state (E2) before entering the economizer to absorb heat from exhaust gas at state (EXH-IN) then water and exhaust gas leave the economizer at state (E3) and (EXH-OUT), respectively. Water at state (E3) flows to the shell and tube heat 
exchanger HE1 to release heat to R245fa then water and R245fa leave the heat exchanger at state (E4) and (5), respectively. The R245fa fluid flows thought the screw expander to produce work to generate electricity and R245fa leaves the expander at state (6) then R245fa flows to condenser to condense R245fa back to liquid at state (1) again. The cooling water at inlet condenser at state (CW-IN) leaves the condenser at (CW-OUT) state.

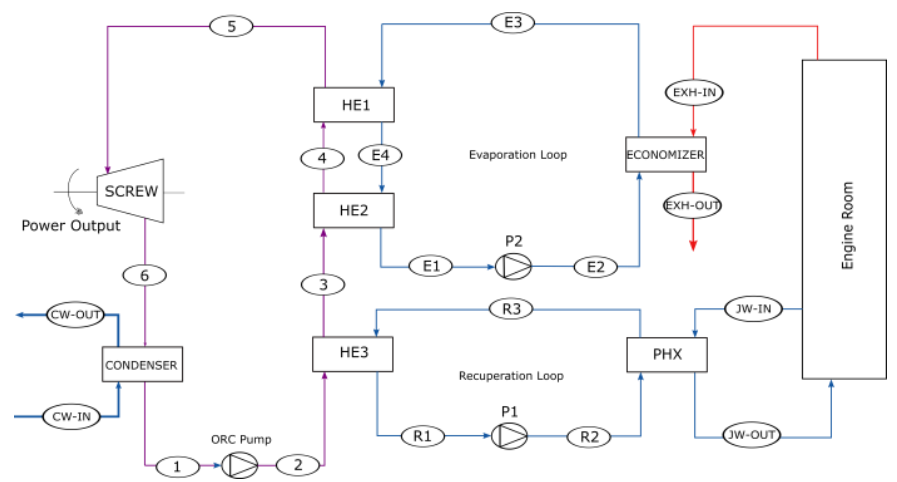

Fig. 1. Schematic Diagram of the ORC System

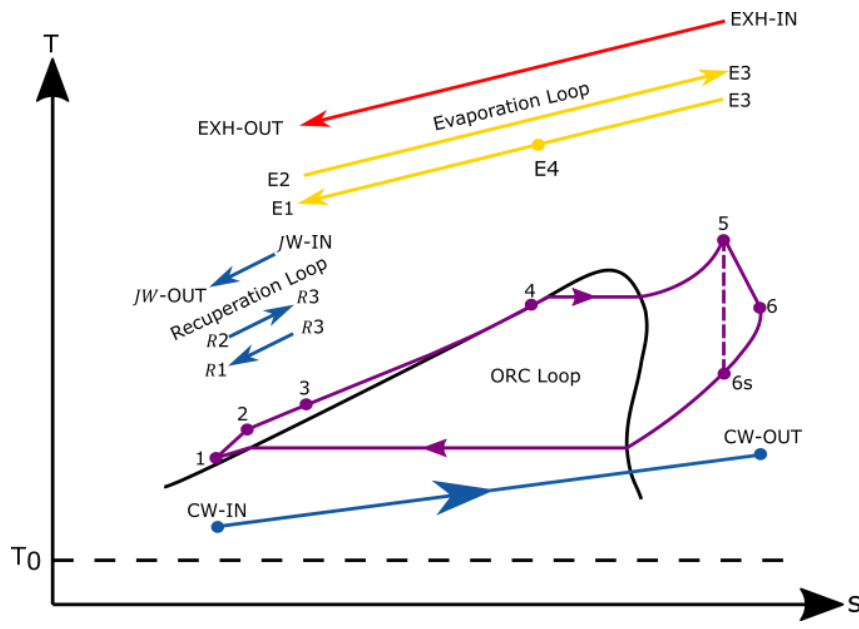

Fig. 2. T-s Diagram of the ORC System

There are 3 types of heat exchanger inside the model and its main practical parameters for simulation are shown in Table II, III, and IV for shell and tube heat exchanger (HE1, HE2, and HE3), plate heat exchanger (PHX, and COND) and air cooled heat exchanger (ECONOMIZER), respectively.

TABLE II: SHELL AND TUBE EXCHANGER PARAMETERS

\begin{tabular}{lcccc}
\hline \multicolumn{1}{c}{ Parameter } & HE1 & HE2 & HE3 & Unit \\
\hline Shell inner diameter/ & $586 / 610$ & $402 / 426$ & $357 / 377$ & $\mathrm{~mm}$ \\
Shell outer diameter & & & & \\
Tube length & 3,480 & 3,440 & 3,450 & $\mathrm{~mm}$ \\
Baffle spacing & 750 & 172 & 172 & $\mathrm{~mm}$ \\
Number tube/Pass & $570 / 1$ & $295 / 1$ & 2,231 & - \\
TEAM type & A-E-L & B-E-L & B-E-L & - \\
Location of hot fluid & Tube side & Tube side & Tube side & - \\
\hline \hline
\end{tabular}

TABLE III: Plate HeAT EXCHANGER PARAMETERS

\begin{tabular}{lccc}
\hline \multicolumn{1}{c}{ Parameter } & PHX & COND & Unit \\
\hline Horizontal port centers distance & 225 & 632 & $\mathrm{~mm}$ \\
Vertical port centers distance & 850 & 2,574 & $\mathrm{~mm}$ \\
Plate thickness & 0.5 & 0.6 & $\mathrm{~mm}$ \\
Compressed plate pitch & 3.1 & 5.1 & $\mathrm{~mm}$ \\
Port diameter & 100 & 391.92 & $\mathrm{~mm}$ \\
Plate width & 460 & $1,038.35$ & $\mathrm{~mm}$ \\
Number of plates & 94 & 241 & - \\
\hline \hline
\end{tabular}

TABLE IV: ECONOMIZER PARAMETERS

\begin{tabular}{lcc}
\hline \multicolumn{1}{c}{ Parameter } & & $\begin{array}{c}\text { Uni } \\
\mathrm{t}\end{array}$ \\
\hline Bays per unit & 3 & - \\
Number of bundles & 2 & - \\
Tube length & 3,000 & $\mathrm{~mm}$ \\
Tube outer diameter & 25.4 & $\mathrm{~mm}$ \\
Number of tube rows & 8 & $\mathrm{~mm}$ \\
Number of tubes/passes & $384 / 1$ & - \\
\hline \hline
\end{tabular}

\section{THERMODYNAMIC ANALYSIS}

The energy balance of the system can be expressed as equation Eq. (1). $Q_{I N}$ represents energy entering the system whereas $Q_{O U T}$ represents energy leaving the system.

$$
\left|Q_{I N}-Q_{O U T}\right|=0
$$

The equation of energy balance can be expanded to clarify the components of $Q_{I N}$ and $Q_{O U T}$ as shown by Eq. (2).

$$
\left|Q_{E X H}+Q_{J W}+P_{O R C}-Q_{C O N D}-P_{E X P}\right|=0
$$

Energy entering the system consists of absorbed waste heats from exhaust gas $\left(Q_{E X H}\right)$ and jacket water $\left(Q_{J W}\right)$, respectively. $P_{O R C}$ is electricity consumption of ORC pump. Energy leaving the system consists of rejected heat by condenser $\left(Q_{C O N D}\right)$ and screw expander work $\left(P_{E X P}\right)$ while other losses are ignored. The screw expander was assumed to have a constant isentropic efficiency $\left(\eta_{E X P}\right)$ to equal 0.55 and the internal structure of screw expander was ignored. The pumps in recuperation loop and boiling loop consume small amount of energy and can be ignored while the ORC pump in ORC loop consumes much more energy and its efficiency is up to the pump characteristic curve. The expansion power and isentropic efficiency of expander can be expressed as Eq. (3) and Eq. (4), respectively, and $\dot{m}$ represents mass flow rate of working fluid R245fa in the ORC loop.

$$
P_{E X P}=\dot{m}\left(h_{5}-h_{6}\right)
$$




$$
\eta_{E X P}=\frac{h_{5}-h_{6}}{h_{5}-h_{6 s}}
$$

The recovery efficiency or $1^{\text {st }}$ efficiency is the ratio between useful work and absorption heat can be written as Eq. (5)

$$
\eta_{1 s t}=\frac{P_{E X P}}{Q_{E X H}+Q_{J W}}
$$

In order to analyze $2^{\text {nd }}$ efficiency, the term of exergy must be introduced. Exergy is the maximum theoretical useful work that a system could produce when interacts only with its environmental until thermodynamic equilibrium state is reached the dead state. In this paper, the dead state temperature is assumed to be $300 \mathrm{~K}\left(T_{0}\right)$. Then exergy can be expressed for any steam state (i) as in Eq. (6) when potential and kinetic exergy are omitted.

$$
\dot{E}_{i}=\dot{m}_{i}\left[\left(h_{i}-h_{0}\right)-T_{0}\left(s_{i}-s_{0}\right)\right]
$$

The net exergy rate enters the system $\left(\dot{E}_{I N}\right)$ as is Eq. (7). It is the summation of the net exergy rate of exhaust gas $\left(\dot{E}_{E X H}\right)$ and jacket water $\left(\dot{E}_{J W}\right)$ together with electrical energy consumption of ORC pump $\left(P_{O R C}\right)$.

$$
\dot{E}_{I N}=\dot{E}_{E X H}+\dot{E}_{J W}+P_{O R C}
$$

The Eq. (7) can be clarified as followed. The net exergy rate of exhaust gas entering the system $\left(\dot{E}_{E X H}\right)$ can be expressed as Eq.

(8), when $\dot{m}_{E X H}$ represents mass flow rate of exhaust gas.

$$
\begin{aligned}
\dot{E}_{E X H}= & \dot{m}_{E X H}\left[\left(h_{E X H-I N}-h_{E X H-O U T}\right)\right. \\
& \left.-T_{0}\left(s_{E X H-I N}-s_{E X H-O U T}\right)\right]
\end{aligned}
$$

The net exergy rate of jacket water entering the system $\left(\dot{E}_{J W}\right)$ can be expressed as Eq. (9), when $\dot{m}_{J W}$ represents mass flow rate of jacket water.

$$
\begin{aligned}
\dot{E}_{J W}= & \dot{m}_{J W}\left[\left(h_{J W-I N}-h_{J W-O U T}\right)\right. \\
& \left.-T_{0}\left(s_{J W-I N}-s_{J W-O U T}\right)\right]
\end{aligned}
$$

Considering the exergy losses over the process, the net exergy loss is the summation of exergy losses in all heat exchangers, pumps, and the screw expander. So it can be written as Eq. (10).

$$
\dot{I}=\dot{I}_{E X H-W F}+\dot{I}_{J W-W F}+\dot{I}_{C O N D}+\dot{I}_{E X P}+\dot{I}_{P}
$$

The total exergy loss of Eq. (10) can be clarified as followed. The exergy loss in the heat exchanging process between exhaust gas and working fluid $\left(\dot{I}_{E X H-W F}\right)$ is the summation of exergy losses in the 3 heat exchangers including economizer, HE1, and HE2 as shown in Eq. (11)

$$
\dot{I}_{E X H-W F}=\left(\dot{E}_{E X H-I N}-\dot{E}_{E X H-O U T}\right)-\left(\dot{E}_{5}-\dot{E}_{3}\right)
$$

The exergy loss in the heat exchanging process between jacket water and working fluid $\left(\dot{I}_{J W-W F}\right)$ is the summation of exergy losses in the 2 heat exchangers including PHX, and HE3 as shown in Eq. (12)

$$
\dot{I}_{J W-W F}=\left(\dot{E}_{J W-I N}-\dot{E}_{J W-O U T}\right)-\left(\dot{E}_{3}-\dot{E}_{2}\right)
$$

The exergy loss in the condensation process between working fluid and cooling water can be expressed as shown in Eq. (13)

$$
\dot{I}_{C O N D}=\left(\dot{E}_{6}-\dot{E}_{1}\right)-\left(\dot{E}_{C W-O U T}-\dot{E}_{C W-I N}\right)
$$

Exergy loss as a result of non-isentropic compression of ORC pump is defined as Eq. (14)

$$
\dot{I}_{P}=\dot{m}\left[T_{0}\left(s_{2}-s_{1}\right)\right]
$$

Exergy loss due to of non-isentropic expansion process in screw expander as Eq. (15)

$$
\dot{I}_{E X P}=\dot{m}\left[T_{0}\left(s_{6}-s_{5}\right)\right]
$$

The exergy efficiency of the ORC system can be defined as Eq. (16)

$\eta_{2 n d}=\frac{P_{E X P}}{\dot{E}_{I N}}$

To investigate each component, the fuel and product exergy concept is applied. The exergy of product $\left(\dot{E}_{P, j}\right)$ is the desired output exergy while the exergy of fuel $\left(\dot{E}_{F, j}\right)$ is the input exergy for any component $\mathrm{j}$. Generally fuel exergy could not be totally converted to product exergy thus exergy loss occurs and this relationship can be expressed as Eq. (17)

$$
\dot{E}_{P, j}=\dot{E}_{F, j}-\dot{E}_{L, j}
$$

Apply fuel and product exergy to analyse exergy efficiency for each component and can be expressed as in table V. 
TABLE V: COMPONENTS EXERGY ANALYSIS

\begin{tabular}{lll}
\hline Component & $\dot{E} x_{F}$ & $\dot{E} x_{P}$ \\
\hline ORC PUMP & $P_{\text {ORC }}$ & $\dot{E} x_{2}-\dot{E} x_{1}$ \\
HE3 & $\dot{E} x_{R 3}-\dot{E} x_{R 1}$ & $\dot{E} x_{3}-\dot{E} x_{2}$ \\
HE2 & $\dot{E} x_{B 4}-\dot{E} x_{B 1}$ & $\dot{E} x_{4}-\dot{E} x_{3}$ \\
\multirow{2}{*}{${ }_{\text {HE1 }}$} & $\dot{E} x_{B 3}-\dot{E} x_{B 4}$ & $\dot{E} x_{5}-\dot{E} x_{4}$ \\
Screw Expander & $\dot{E} x_{5}-\dot{E} x_{6}$ & $P_{E X P}$ \\
COND & $\dot{E} x_{6}-\dot{E} x_{1}$ & $\dot{E} x_{C W-O U T}-\dot{E} x_{C W-I N}$ \\
PHX & $\dot{E} x_{J W-I N}-\dot{E} x_{J W-O U T}$ & $\dot{E} x_{R 3}-\dot{E} x_{R 2}$ \\
ECONOMIZER & $\dot{E} x_{E X H-I N}-\dot{E} x_{E X H-O U T}$ & $\dot{E} x_{E 3}-\dot{E} x_{E 2}$ \\
\hline \hline
\end{tabular}

\section{RESULTS AND DISCUSSION}

\subsection{Waste Heat Absorption}

The waste heat absorption $Q_{E X H}$ and $Q_{J W}$ can be plotted with variation of evaporating pressure as shown in Fig.3 and the summation of them is shown in Fig.4. The results in Fig.3 show the tendency of heat absorption with variation of the condition of ORC pump. The absorption $Q_{E X H}, Q_{J W}$ and its summation decreases as evaporating pressure increases because of the characteristic of ORC pump. Considering at the lower evaporating pressure, ORC pump gives lower temperature and pressure at state (2) whereas temperature of exhaust and jacket water are fixed and the ORC pump also gives higher volume flow rate of R245fa. These reasons affect directly to heat transfer occur inside the economizer and PHX heat exchanger because the higher temperature difference and higher volume flow rate induce higher heat transfer. On the other hand, considering at the higher evaporating pressure, ORC pump gives higher temperature and pressure at state (2) and also gives lower volume flow rate of $\mathrm{R} 245 \mathrm{fa}$ because the lower temperature difference and lower volume flow rate induce lower heat transfer. From Fig.4, the evaporating pressure is 21 bar and at this point the system can absorb the highest amount of waste heat of $4,769 \mathrm{~kW}$.

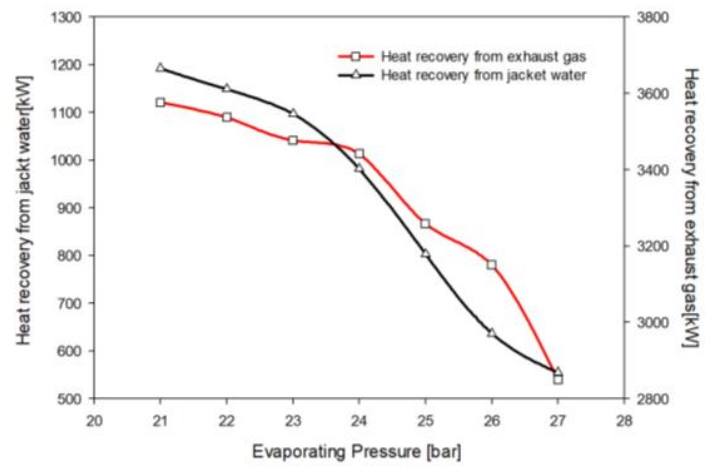

Fig. 3. Heat recovery from exhaust and jacket water

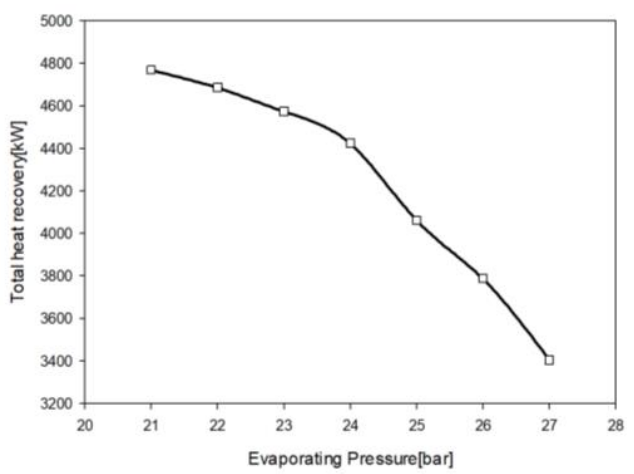

Fig. 4. Total Waste Recovery

\subsection{Expansion Power and Efficiencies}

Fig.5 shows the expansion power $\left(P_{E X P}\right)$ and recovery efficiency $\left(\eta_{1 s t}\right)$ with the variation of evaporating pressure. Considering the Fig.2, starting from the lowest evaporating pressure of 21 bar, expansion power has the lowest value because of the low difference pressure between entering and leaving screw expander even though the flow rate of R245fa is high and low expansion power relates directly to low recovery efficiency. When the evaporating pressure continue to rise as shown in the Fig.5, the expansion power and recovery efficiency increases exponentially until the expansion power reaches its maximum point and can produce the maximum power of 326 $\mathrm{kW}$ at 26 bar. After expansion power passes its maximum point the expansion power drops because the dramatic drop of R245fa flow rate. But recovery efficiency has small change when evaporating pressure is higher than 26 bar and its maximum efficiency is $8.74 \%$ at 27 bar. The stationary recovery efficiency value caused by the simultaneous drops in expansion power and total heat recovery.

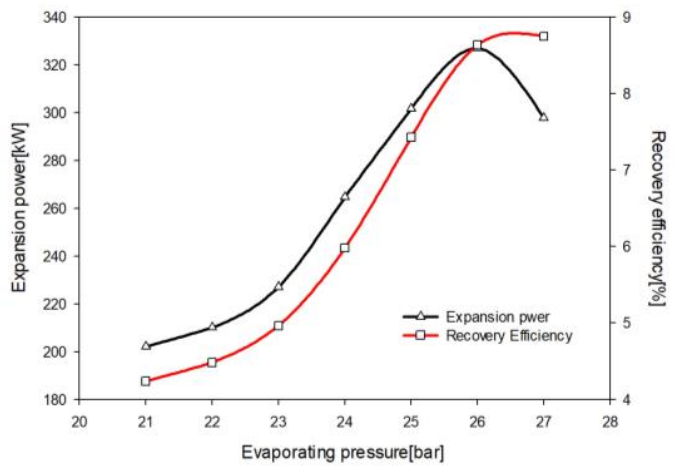

Fig. 5. Expansion power and recovery efficiency

Fig.6 shows the exergy efficiency with the variation of evaporating pressure. The trend of exergy efficiency is similar the recovery trend, but the values can express exactly how much percentage of possible work can be converted to actual work. The highest value of exergy efficiency of the system is $21.45 \%$ at evaporating pressure of $26 \mathrm{bar}$. 


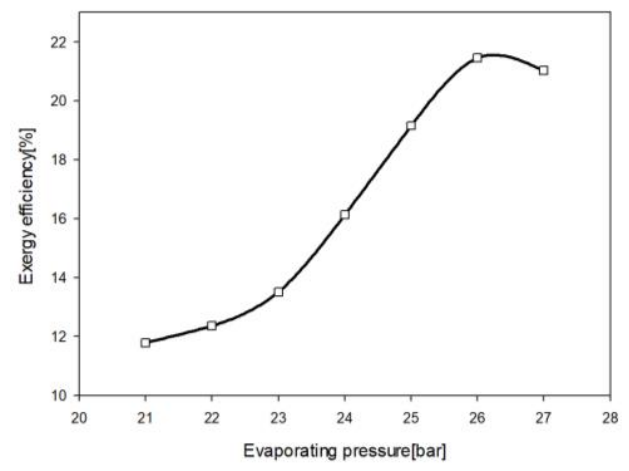

Fig. 6. Exergy efficiency of ORC system

\subsection{Component Exergy Analysis}

Generally, exergy efficiency is used to fine out the possible room that components can be improved. The condition which produces the highest expansion power is selected for analysing exergy analysis of each component. The result is shown in Table.VI. HE1 has the highest exergy efficiency and PHX has the second highest exergy efficiency. The focus of necessary improvement should be rest on the components such as, COND, HE3 and ORC pump that its efficiency almost lower than 50\%. Heat exchangers such as COND and HE3 can be improved by increasing heat transfer area and changing material and pump in ORC loop may be recommended to replace with one more efficient alternative.

TABLE VI: RESUltS OF COMPONENTS EXERGy ANALYSIS

\begin{tabular}{cccc}
\hline \hline Component & $\dot{E} x_{F}(\mathrm{~kW})$ & $\dot{E} x_{P}(\mathrm{~kW})$ & $2^{\text {nd }}$ efficiency (\%) \\
\hline ORC PUMP & 53.188 & 26.654 & 50.09 \\
HE3 & 87.040 & 36.363 & 41.77 \\
HE2 & 301.431 & 196.004 & 60.02 \\
HE1 & 580.866 & 527.893 & 90.88 \\
Screw Expander & 559.867 & 327.338 & 58.46 \\
COND & 222.718 & 57.371 & 25.76 \\
PHX & 96.602 & 86.268 & 89.30 \\
ECONOMIZER & $1,372.730$ & 880.579 & 64.14 \\
\hline \hline
\end{tabular}

\section{CONCLUSIONS}

ORC system is deployed to recovery waste heat in exhaust gas and jacket water to improve efficiency for natural gas engine. Thermodynamic simulations are conducted. The conclusion can be written as followed.

(1) Exhaust and jacket water heat recovery are affected directly to discharged pressure and volume flow rate of R $245 \mathrm{fa}$. The lower discharged pressure and higher volume flow rate induce more waste heat, otherwise induce less.

(2) The ORC system has its maximum expansion power (326 $\mathrm{kW}$ ) at evaporating pressure of $26 \mathrm{bar}$ and it has maximum exergy efficiency of the system of $21.45 \%$. While the maximum recovery efficiency is $8.74 \%$ at evaporating pressure of $27 \mathrm{bar}$ because of dramatic drop of waste heat recovery.

(3) The exergy analysis of each component of the ORC system is analysed. There are still possible rooms to improve the efficiency of system.
(4) The ORC system should be operated at 26 bar of evaporating pressure to produce the highest expansion power with constant waste heat loss.

\section{REFERENCES}

[1] Charles Sprouse III, and Christopher Depcik, "Review of Organic Rankine cycles for internal combustion engine exhaust waste heat recover", Applied Thermal Engineering, Vol.51, pp.711-722, 2013. https://doi.org/10.1016/j.applthermaleng.2012.10.017

[2] Guopeng Yu, Gequn Shu, Hua Tian, Haoqaio Wei, and Lina Liu, "Simulation and Thermodynamic analysis of a bottoming Organic Rankine Cycle(ORC) of diesel engine”, Energy, Vol.51, pp.1-10, 2013. https://doi.org/10.1016/j.energy.2012.10.054

[3] A Mahmoudi, M. Fazli, and M.R. Morad, "A recent review of waste heat recovery by Organic Rankine Cycle", Applied Thermal Engineering, Vol.143, pp.660-675, 2018.

https://doi.org/10.1016/j.applthermaleng.2018.07.136

[4] Bo-Tau Liu, Kuo-Hsiang Chien, and Chi-Chuan Wang, "Effect of working fluid on Organic Rankine cycle for waste heat recovery", Energy, Vol.29, pp.1207-1217, 2002.

https://doi.org/10.1016/j.energy.2004.01.004

[5] Kankeyan Thurairaja, Anusha Wijewardane, Saliya Jayasekara, and Chathura Ranasinghe. "Working Fluid Selection and Performance Evaluation of ORC", Vol.156, pp.244-248, 2018.

https://doi.org/10.1016/j.egypro.2018.11.136

[6] Ho Teng, Garhard Regner, and Chris Cowland, "Waste Heat Recovery of Heavy-Duty Dassel Engines by Organic Rankine Cycle Part I: Hybrid Energy System of Diesel and Rankine Engines", SAE International, 2007. https://doi.org/10.4271/2007-01-0537

[7] Kubo I, "Technical and economic study of Sterling and Rankine cycle bottoming systems for heavy truck diesel engines", U.S. Department of Energy, 1987.

[8] Meng Zhoa, Mingshan Wei, Panpan Song, Zhen Liu, and Zhixing Wang, "Effect of the ORC Operating Conditions on the Engine Performance for an Engine-ORC Combined System", Energy Procedia, Vol.105, pp.662-667, 2017. https://doi.org/10.1016/j.egypro.2017.03.372

[9] R. Cipollone, D. Di Battista, and Bettoja, "Performances of an ORC power unit for Waste Heat Recovery on Heavy Duty Engine", Energy Procedia, Vol.129, pp.770-777, 2017.

https://doi.org/10.1016/j.egypro.2017.09.132

[10] Colin A.Scholes, Minh T.Ho, and Diane E.wiley, "Membrane-Cryogenic Post-Combustion Carbon Capture of Flue Gases from NGCC", Technologies, Vol.4, pp.1-14, 2016.

https://doi.org/10.3390/technologies4020014 